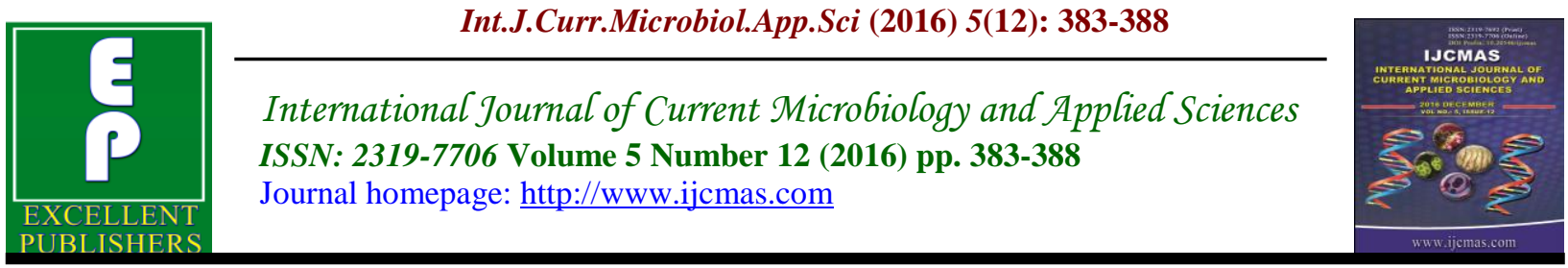

Original Research Article

http://dx.doi.org/10.20546/ijcmas.2016.512.042

\title{
CBNAAT: A Novel Tool for Rapid Detection of MTB and Rifampicin Resistance
}

\author{
V.P. Basavaraj ${ }^{1}$ and R. Rajani ${ }^{2 *}$ \\ Department of Microbiology, Raichur Institute of Medical Sciences, Raichur, Karnataka, India \\ *Corresponding author
}

Keywords

MDRTB,

Rifampicin

resistance,

GeneXpert

MTB/RIF.

\section{Article Info}

Accepted:

18 November 2016

Available Online:

12 December 2016

\section{A B S T R A C T}

Emergence of Multidrug resistant Tuberculosis (MDRTB) has become a significant obstacle for Tuberculosis (TB) control. Rifampicin (RIF) resistance is important indicator of MDRTB. Rapid simultaneous detection of Mycobacterium Tuberculosis (MTB) and RIF resistance are very essential for effective disease management. CBNAAT (Cartridge Based Nucliec Acid Amplification Test) also known as Gene Xpert MTB/RIF assay is a novel diagnostic tool for detection of MTB and RIF resistance. To study the usefulness of CBNAAT for rapid detection of MTB and RIF resistance in MDRTB suspected cases. 1201 sputum samples were collected from MDRTB suspected cases including both new cases and previously treated cases. These were processed using Gene Xpert MTB/RIF assay. The results were statistically analyzed. Out of 1201 sputum samples, MTB was detected in $268(22.31 \%)$ samples and RIF resistance was detected in $30(2.49 \%)$ samples. 2 (33.33\%) RIF resistant samples were from failures, 14(12.17\%) from Smear positive $(\mathrm{S}+)$ at diagnosis/retreatment case, 10(12.65\%) from follow up $\mathrm{S}+$, $1(0.11 \%)$ from HIV presumptive TB case. Combination of mutations ie mutations associated with more than one probe was seen in all the 30 RIF resistant samples. Mutations at 5 different $r p o B$ gene regions are $100 \%$ at $518-523,96.66 \%$ at 507 $511,90 \%$ at $512-518,86.66 \%$ at $523-529$ and $43.33 \%$ at 529-533. Gene Xpert MTB/RIF assay is a good screening tool for diagnosis of MTB and detection of RIF resistance from MDRTB suspected cases within a shorter period.

\section{Introduction}

According to the WHO Tuberculosis report 2015, India, Indonesia and China had the largest number of cases: 23\%,10\% and 10\% of the global total, respectively. Globally, an estimated $3.3 \%$ of new TB cases and $20 \%$ of previously treated cases have MDR-TB (WHO, 2015). The global priorities of TB control are early and improved TB case detection with the capacity to diagnose
MDR TB. As the conventional laboratory methods are slow and cumbersome, Foundation for Innovative New Diagnostics (FIND) introduced cartridge-based nucleic acid amplification assay (Xpert MTB/RIF). It is a molecular test which is fully automated and detects $M$. tuberculosis as well as RIF resistance-conferring mutations directly from sputum samples within two 
hours (WHO, 2011). This Gene X pert was installed in our institute (Raichur institute of Medical Sciences) in March 2016 under Revised National Tuberculosis Control Programme (RNTCP) TB Xpert project supported by WHO-STOP TB partnership-UNITAID.

The surrogate marker for MDRTB is RIF resistance. The presence of mutations in 81 bp RIF resistance determining region (RRDR) of the $r p o B$ gene, corresponding to codons 507-533 (Escherichia coli numbering system), which codes for a beta subunit of RNA polymerase of MTB is the genetic basis of RIF resistance (in approximately 95\% cases) (Ramaswamy et al., 1998).

MDRTB burden and mutations responsible for drug resistance vary from country to country, region to region as per the studies conducted in diverse geographical areas (Purwar et al., 2011). But there is no enough information about this aspect from this part of Karnataka; therefore the study was conducted by using Xpert MTB/RIF assay.

\section{Materials and Methods}

The study was carried out in the RNTCP lab attached to Department of Microbiology, Raichur institute of Medical Sciences, Raichur, Karnataka, India. Sputum samples were received from various health centres of Raichur district (Sindhanoor, Sirawar, Maanvi, Yadgir, Devdurga, Raichur) and also referred cases from District TB centres (DTC), Antiretroviral (ART) centres. The study period was from March 2016 to August 2016. A total of 1201 sputum samples of suspected MDRTB cases including both new cases and previously treated cases were included. All the sputum samples were collected in special falcon tubes after through rinsing of the oral cavity with clean water. All the details of the patients like Name, Address, Age, Sex, History of contact, HIV status, Treatment received and Name of the referring centre were noted down.

Sputum specimens were processed by Xpert MTB/RiF assay (Cepheid-Sunnyvale-USA), as per the guidance document given by Central TB division, Government of India (RNTCP, 2013; RNTCP, 2012). rpoB gene of $M$. tuberculosis was extracted and amplified as it accounts for more than $95 \%$ of mutations associated with RIF resistance. It ensures high degree of specificity by usage of three specific primers and 5 unique molecular probes (WHO, 2014). The results can be distinguished as MTB detected, MTB not detected, RIF resistance detected; RIF resistance not detected; RIF resistance indeterminate; or invalid with the help of positive beacons and their detection timing, sample processing controls (WHO, 2013; Weyer et al., 2013). The manual steps involved in the assay are adding sample reagent to liquefy sputum and sample loading in the catridge (RNTCP, 2013). The test procedure is made biosafe by tuberculocidal property of the assay's sample reagent (WHO, 2013).

\section{Results and Discussion}

Out of 1201 sputum samples, MTB was detected in $268(22.31 \%)$ samples and RIF was found to be resistant in 30 (2.49\%). (Table 1)

MTB and RIF resistance was more commonly seen in sputum samples from males than females. 2(33.33\%) RIF resistant samples were from failures, $14(12.17 \%)$ from $\mathrm{S}+$ at diagnosis/ retreatment case, $10(12.65 \%)$ from follow up $\mathrm{S}+, 1(0.11 \%)$ from HIV presumptive TB case and $3(6.66 \%)$ from others. (Table 1 ) 
Highest percentage of MTB and RIF resistance was seen in the age group of 5160 yrs. Elderly had least RIF resistance. (Table 1)

$38(3.16 \%)$ samples showed "errors" and 28 $(2.33 \%)$ samples showed "no results". All these samples were retested, and valid results were obtained except in 3 (could not be processed due to insufficient material in the second sample also).

The combinations of mutations were seen in all the 30 RIF resistant samples detected by 5 different probes $(\mathrm{A}, \mathrm{B}, \mathrm{C}, \mathrm{D}, \mathrm{E})$. In 5 samples, mutation was seen in all the probes. All the $30(100 \%)$ had mutations at probe C, 29(96.66\%) at probe A, 27(90\%) at probe $\mathrm{B}, 26(86.66 \%)$ at probe $\mathrm{D}$, $13(43.33 \%)$ at probe E. Accordingly, the mutations at 5 different $r p o B$ gene regions are $100 \%$ at $518-523,96.66 \%$ at $507-511$, $90 \%$ at $512-518,86.66 \%$ at $523-529$ and $43.33 \%$ at $529-533$. (Table 1)

In this study, we observed RIF resistance which is a surrogate marker of MDR-TB in $2.49 \%$ of suspected cases of MDR-TB of raichur region. These findings are similar to reports from place nearby raichur ie from Krishna, Andhra Pradesh (2\%) (Giridhar et al., 2014). However, higher prevalence of MDR-TB has been reported in other Indian studies (Lucknow 27.8\% (Jain et al., 2014), New Delhi 17.9\% (Singhal et al., 2015), and Central India 17\%) (Desikan et al., 2014).

Our several findings are consistent with TB details: for example, males have higher MTB diagnostic rates compared to females (Balasubramanian et al., 2004). Elderly have lowest risk of MDR-TB compared to other age groups, may be due to reduced survival amongst those with TB infection (ICMR, 2012).
RIF resistance was most commonly seen in failures $(33.33 \%)$ in this study. Other studies showed $23.47 \%$ from Kerala (Ganguly et al., 2015), 17\% from South India (Santha et al., 2005).

Retreatment cases/smear positive at diagnosis was $12.17 \%$ among RIF resistant cases in this study. In a study by $\mathrm{S} \mathrm{K}$ Sharma et al., (Sharma et al., 2011) drug resistance was found in $20 \%$ of Retreatment cases at diagnosis which is high compared to our study.

$0.11 \%$ among RIF resistant cases was found to be HIV seropositive in our study. HIV seropositivity was observed by Deivanayagam et al., (Deivanayagam et al., 2002 ) in $4.42 \%$ of MDRTB patients.

The most common RRDR rpoB gene mutations were in the gene region 518-523, recognized by Probe C. But Mboowa et al., observed most common mutation in codon 531 (58\%) followed by 513 (25\%), 526 $(8 \%)$, and $511(8 \%)$ designed by probes $\mathrm{E}$, B, D, and A. (Mboowa et al., 2014). Mani et $a l$, reported that the codons most commonly involved in these mutations were $531(53 \%)$ and $526(19 \%)$ in a study from South India (Mani et al., 2001). The resistant mutants isolated more frequently in clinical practice have higher mean relative fitness and their prevalence depend on their ability to survive (Billington et al., 1999). Combinations of muations (all the probes) were observed in all the 30 isolates of the RIF resistant samples in the present study. While, Singhal et al., found 6 strains (6/366) with more than one mutation (Singhal et al., 2015). Probably, mutations continue to arise due to the ability of MTB to adapt to drug exposure (Mani et al., 2001). The results were statically analyzed $(\mathrm{p}<0.0005)$. 
Table.1 Demographic profile of study participants

\begin{tabular}{|c|c|c|c|c|c|c|}
\hline & $\mathbf{N}$ & $\%$ of $\mathrm{N}$ & TB & $\%$ (of row) & $\begin{array}{l}\text { RIF } \\
\text { resistance }\end{array}$ & $\%$ (of row \\
\hline $\begin{array}{l}\text { Total } \\
\text { Gender }\end{array}$ & 1201 & $100 \%$ & 268 & $22.31 \%$ & 30 & $2.49 \%$ \\
\hline Male & 645 & $53.70 \%$ & 197 & $30.54 \%$ & 22 & $3.41 \%$ \\
\hline Female & 556 & $46.29 \%$ & 71 & $12.76 \%$ & 8 & $1.43 \%$ \\
\hline Age (yrs) & & & & & & \\
\hline $19-30$ & 315 & $26.22 \%$ & 71 & $22.53 \%$ & 10 & $3.17 \%$ \\
\hline $31-40$ & 484 & $40.29 \%$ & 92 & $19 \%$ & 13 & $2.68 \%$ \\
\hline $41-50$ & 260 & $21.64 \%$ & 56 & $21.53 \%$ & 1 & $0.38 \%$ \\
\hline $51-60$ & 98 & $8.15 \%$ & 34 & $34.69 \%$ & 6 & $6.12 \%$ \\
\hline$>61$ & 44 & $3.66 \%$ & 15 & $34.09 \%$ & 0 & $0 \%$ \\
\hline $\begin{array}{l}\text { RNTCP MDR } \\
\text { suspect criteria }\end{array}$ & & & & & & \\
\hline 1: Failure & 6 & $0.49 \%$ & 3 & $50 \%$ & 2 & $33.33 \%$ \\
\hline $\begin{array}{l}\text { 2: Retreatment } \\
\text { case,S+ at } 4^{\text {th }} \\
\text { month }\end{array}$ & 4 & $0.33 \%$ & 4 & $100 \%$ & 0 & $0 \%$ \\
\hline $\begin{array}{l}\text { 3:Contact } \\
\text { known } \\
\text { case }\end{array}$ & 1 & $0.08 \%$ & 0 & $0 \%$ & 0 & $0 \%$ \\
\hline $\begin{array}{l}\text { 4:S+at diagnosis, } \\
\text { retreatment case }\end{array}$ & 115 & $9.57 \%$ & 99 & $86.08 \%$ & 14 & $12.17 \%$ \\
\hline $\begin{array}{l}\text { 5:Any follow up } \\
\text { S+ }\end{array}$ & 79 & $6.57 \%$ & 65 & $82.27 \%$ & 10 & $12.65 \%$ \\
\hline $\begin{array}{l}\text { 6:Smear } \quad-\text { at } \\
\text { diagnosis, } \\
\text { retreatment case }\end{array}$ & 83 & $6.91 \%$ & 20 & $24.09 \%$ & 0 & $0 \%$ \\
\hline 7 : HIV TB case & 31 & $2.58 \%$ & 9 & $29.03 \%$ & 0 & $0 \%$ \\
\hline $\begin{array}{l}\text { 8:HIV } \\
\text { presumptive } \\
\text { case }\end{array}$ & 837 & $69.69 \%$ & 56 & $6.69 \%$ & 1 & $0.11 \%$ \\
\hline 11: Others* & 45 & $3.74 \%$ & 12 & $26.66 \%$ & 3 & $6.66 \%$ \\
\hline
\end{tabular}

(Criteria 9: Presentation paediatric, Criteria 10: Presentation extrapulmonary, both are excluded from the study)

Need of nonstop power supply, Ambient temperature not exceeding $30^{\circ} \mathrm{C}$, incomplete sensitivity for smear-negative TB, inability to detect resistance to isoniazid and other drugs, Biosafety measures comparable to smear microscopy, Waste disposal system for cartridges, Trained laboratory, Annual calibration of the Xpert modules are the few limiatations with the CBNAAT (Vassall et al., 2011).

Small sample size is the limitation in this study. But data regarding prevalence of TB and its drug resistance status at national and 
State level are the need of the hour. One more limitation of the study was that no gold standard was used for the comparison of Xpert MTB/RIF assay results.

In conclusion, Xpert MTB/RIF is a better screening tool for simultaneous detection of MTB and RIF resistance in a shorter period of time, and this could help improve early recognition of $\mathrm{MDR}-\mathrm{TB}$ and prevention of its further transmission in raichur region of Karnataka. From this study we conclude that RIF resistance cases are found in significant no. of MDR TB suspects using CB NAAT (GeneXpert MTB/RIF). Most of the resistant patients are failure cases. HIV patients should also be screened for MDRTB. Although Xpert MTB/RIF assay tells about pattern of mutation in rpoB gene, DNA sequencing for detailed study is a must.

\section{Acknowledgment}

I would like to express my profound gratitude to all the participants for their cooperation and for their immense faith they reposed in me.

Conflict of Interest: None to declare

\section{References}

Balasubramanian, R., R. Garg, T. Santha, P.G. Gopi, R. Subramani, Chandrasekaran, V. et al. 2004. Gender disparities in tuberculosis: report from a rural DOTS programme in south India, Int. J. Tuberc. Lung Dis., 8: 323-32, Available: http://www.ncbi.nlm.nih.gov/pubmed/151 39471 .

Billington, O.J., T.D. McHugh and Gillespie S.H. 1999. Physiological cost of rifampin resistance induced in vitro in Mycobacterium tuberculosis. Antimicrob. Agents Chemother., 43: 1866-9.

Deivanayagam, C.N. et al. 2002. Prevalence of acquired MDR-TB and HIV co-infection.
Indian J. Chest Dis. Allied Sci., 44(4): $237-42$.

Desikan, P., D.S. Chauhan, P. Sharma, N. Panwalkar, P. Yadav and Ohri B.S. 2014. Clonal diversity and drug resistance in Mycobacterium tuberculosis isolated from extra-pulmonary samples in central India - A pilot study. Indian J. Med. Microbiol., 32: 434-7

Facing the Reality of Drug-Resistant Tuberculosis in India: Challenges and Potential Solutions: Summary of a Joint Workshop by the Institute of Medicine, the Indian National Science Academy, and the Indian Council of Medical Research, (2012) Available: http://www.ncbi.nlm.nih.gov/books/NBK 100386/

Ganguly, J., S. Ray, S. Nandi S, et al. 2015. A study to evaluate pattern of rifampicin resistance in cases of sputum positive pulmonary tuberculosis. J. Evolution of Med and Dent. Sci., 4: 4762-8.

Giridhar, M.K., V. Rao and Setty C.R. 2014. Study of Prevalence of Multi-Drug Resistant Tuberculosis in a Tertiary Care Hospital. Sch. J. App. Med. Sci., 2(1C): 269-273.

Guidance document for use of Catridge BasedNucleic Acid Amplification Test (CBNAAT) under Revised National TB Control Programme (RNTCP) issued central TB division, directorate general of health services September 2013.

Jain, A., P. Diwakar and Singh U. 2014. Declining trend of resistance to first-line anti-tubercular drugs in clinical isolates of Mycobacterium tuberculosis in a tertiary care North Indian hospital after implementation of revised national tuberculosis control programme. Indian J. Med. Microbiol., 32: 430-3.

Laboratory Services for Progammatic Management of Drug Resistant Tuberculosis, Ch.4. Guidelines on Programmatic Management of Drug Resistant TB (PMDT) in India. Revised National Tuberculosis Control Programme. May 2012. 
Mani, C., N. Selvakumar, S. Narayanan and Narayanan, P.R. 2001. Mutations in the rpoB gene of multidrug-resistant Mycobacterium tuberculosis clinical isolates from India. J. Clin. Microbiol., 39: 2987-90.

Mboowa, G., C. Namaganda and Ssengooba W. 2014. Rifampicin resistance mutations in the 81 bp RRDR of rpoB gene in Mycobacterium tuberculosis clinical isolates using Xpert ${ }^{\circledR} \quad \mathrm{MTB} / \mathrm{RIF}$ in Kampala, Uganda: A retrospective study. BMC Infect. Dis., 14: 481.

Purwar, S., S. Chaudhari, V.M. Katoch, A. Sampath, P. Sharma, Upadhyay, P., et al. 2011. Determination of drug susceptibility patterns and genotypes of Mycobacterium tuberculosis isolates from Kanpur district, North India. Infect. Genet. Evol., 11: 469-75.

Ramaswamy, S., and Musser, J.M. 1998. Molecular genetic basis of antimicrobial agent resistance in Mycobacterium tuberculosis: 1998 update. Tuber. Lung Dis., 79: 3-29.

Santha, T., P.G. Gopi, Rajeswari R, et al. 2005. Is it worth treating Category I failure patients with Category II regimen? Indian J. Tuberc., 52: 203-206.

Sharma, S.K. et al. 2011. Prevalence of multidrug-resistant tuberculosis among Category II pulmonary tuberculosis patients. Indian J. Med. Res., 133: 312315.

Singhal, R., V.P. Myneedu, J. Arora, N.Singh, M. Bhalla, Verma A, et al. 2015. Early detection of multi-drug resistance and common mutations in Mycobacterium tuberculosis isolates from Delhi using
GenoType MTBDRplus assay. Indian J. Med. Microbiol., 33 Suppl(1): 46-52.

Vassall, A., S. van Kampen, H. Sohn, J.S. Michael, John, K.R., et al. 2011. Rapid Diagnosis of Tuberculosis with the Xpert MTB/RIF Assay in High Burden Countries: A Cost- Effectiveness Analysis. PLoS Med., 8(11): e1001120. doi:10.1371/journal. pmed.1001120.

Weyer, K., F. Mirzayev, G.B. Migliori, W.V. Gemert, L. D'Ambrosio and Zignol, M. 2013. Rapid molecular TB diagnosis: evidence, policy making and global implementation of Xpert MTB/RIF. ERJ, 42(1): 252-71.

World Health Organization, 2013. Automated Real-Time Nucleic Acid Amplification Technology for Rapid and Simultaneous Detection of Tuberculosis and Rifampicin Resistance: Xpert MTB/ RIF Assay for the Diagnosis of Pulmonary and Extrapulmonary TB in Adults and Children: Policy Update. Geneva.

World Health Organization. 2011. Automated Real-Time Nucleic Acid Amplification Technology for Rapid and Simultaneous Detection of Tuberculosis and Rifampicin Resistance, Xpert MTB/RIF system : Policy statement. Geneva.

World Health Organization. 2015. Global tuberculosis report, 2015. WHO/HTM/TB/2015.22. Geneva, Switzerland: WHO.

Xpert MTB/RIF implementation manual: technical and operational 'how-to'; practical considerations. Report no.WHO/HTM/TB/2014.1.

\section{How to cite this article:}

Basavaraj, V.P., and Rajani, R. 2016. CBNAAT: A Novel Tool for Rapid Detection of MTB and Rifampicin Resistance. Int.J.Curr.Microbiol.App.Sci. 5(12): 383-388.

doi: http://dx.doi.org/10.20546/ijcmas.2016.512.042 